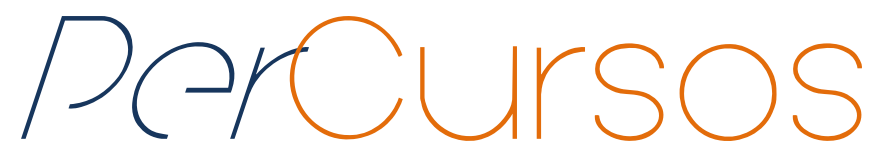

\title{
Os usos e aplicações do Google Earth como recurso didático no ensino de Geografia
}

\section{Resumo}

As tecnologias utilizadas em estudos geográficos tornaram-se cada vez mais frequentes nas classes de professores de Geografia e provaram sua eficiência no processo de ensino-aprendizagem. Quando desenvolvido e utilizado a partir de uma preocupação teórica e metodológica, focalizando a experiência do espaço e as experiências dos alunos, produtos educacionais construídos a partir da geotecnologia despertam e encorajam estudantes de diferentes níveis educacionais sobre a importância do conhecimento geográfico em várias situações cotidianas. O Google Earth é um recurso de ensino útil durante as aulas de geografia, especialmente na cartografia escolar. Nele, o professor pode encontrar várias informações iconográficas em diferentes perspectivas e / ou dimensões, escalas e momentos históricos, permitindo o uso de maneira multivariada e interdisciplinar, dando ao aluno uma compreensão mais profunda de diferentes conteúdos trabalhados em aula. Este artigo é um relatório de experiências da utilização de ferramentas do Google Earth nas aulas de geografia, com alunos do ensino médio assistidos pelo PIBID na Escola Estadual Maria de Lourdes Rebelo, em Teresina / PI, em 2015. Essas ferramentas constituem subsídios para a construção de uma nova prática pedagógica no ensino da geografia e possibilitam o aprendizado dos conteúdos de forma mais intuitiva pelos alunos em sala de aula, uma vez que as ferramentas disponíveis no Google Earth são muito mais interativas, com intervenção direta do aluno em situações de seu próprio contexto social.

Palavras-chave: Google Earth. Ensino de Geografia. Geotecnologia.
Armstrong Miranda Evangelista

Doutor em Educação pela

Universidade Federal do Ceará -

UFC. Professor da Universidade

Federal do Piauí - UFPI.

Brasil

armstrong@ufpi.edu.br

\section{Maria Valdirene Araújo Rocha Moraes \\ Doutora em Geociências pela \\ Universidade Federal de \\ Pernambuco - UFPE. Professora da Univ. Federal do Piauí - UFPI. \\ Brasil \\ valdirene@ufpi.edu.br}

\author{
Carlos Vinícius Ribeiro Silva \\ Graduado em Geografia pela \\ Univ. Federal do Piauí - UFPI. \\ Brasil \\ vsilvati@gmail.com
}

\section{Para citar este artigo: \\ EVANGELISTA, Armstrong Miranda; MORAES, Maria Valdirene Araújo Rocha; SILVA, Carlos Vinícius Ribeiro. Os usos e aplicações do Google Earth como recurso didático no ensino de Geografia. Revista PerCursos, Florianópolis, v. 18, n.38, p. 152 - 166, set./dez. 2017.}

\section{DOI: $\mathbf{1 0 . 5 9 6 5 / 1 9 8 4 7 2 4 6 1 8 3 8 2 0 1 7 1 5 2}$}

http://dx.doi.org/10.5965/1984724618382017152 


\title{
The Google Earth uses and applications as Didactic Resource in Geography Teaching
}

\begin{abstract}
The technologies used in geographic studies have become increasingly frequent in classes of Geography teachers, and have proven their efficiency in the teaching-learning process. When developed and used from a theoretical and methodological concern, focusing on the experience of space and the experiences of students, educational products built from the geotechnology, awake and encourage students of different educational levels about the importance of geographical knowledge in various everyday situations. Google Earth is a useful teaching resource during geography classes, especially in school cartography. There the teacher can find several iconographic information in different perspectives and / or dimensions and historical moments, allowing its use in a multivariate and interdisciplinary way, providing the student with a deeper understanding of different contents worked in class. This paper is a report of experiences with the use of Google Earth tools in geography classes with high school students assisted by PIBID in the State School Maria de Lourdes Rêbelo in Teresina / PI, in 2015. These tools constitute subsidies for the construction of a new pedagogical practice in geography teaching aimed at enabling a more intuitive learning of the contents by the students in the classroom, as the tools available in Google Earth are much more interactive, with the direct intervention of the student in situations within their own social context.
\end{abstract}

Keywords: Google Earth. Geography Teaching. Geotechnology. 


\section{Introdução}

A Geografia enquanto disciplina integrante do currículo escolar da educação básica deve contribuir, através das geotecnologias como ferramentas didáticas, para a inserção tecnológica e para o estudo/reflexão do espaço geográfico. Deve-se ressaltar que a utilização dessas ferramentas, como um fim em si mesmo, não contribui para a transformação social e aprendizado real do aluno, mas é necessário repensar sempre de forma crítico-reflexiva as práticas de ensino, para que se obtenham resultados satisfatórios no processo de ensino-aprendizagem em geografia.

Tomando por base os Parâmetros Curriculares Nacionais (BRASIL, 1999), a Geografia deve fazer uso de imagens e recorrer a diferentes linguagens na busca de informações, como forma de expressar suas interpretações, hipóteses e conceitos. Assim, por exemplo, o estudo da cartografia auxilia não somente na compreensão dos mapas, mas também no desenvolvimento da capacidade de representação e interpretação do espaço geográfico de forma holística. É justamente por intermédio dos diferentes tipos de linguagens que é possível sintetizar informações, expressar conhecimentos, estudar situações, entre outras coisas, sempre envolvendo a ideia da produção do espaço: sua organização e distribuição.

Desta forma, ao entender que educar é uma prática que prepara para o mundo, a escola deve refletir e considerar as questões relativas ao uso de tecnologias como recursos didáticos, que motivam e auxiliam no aprendizado. Não se trata de substituir o professor, e sim, de disponibilizar uma ferramenta adicional para o desenvolvimento do ensino de Geografia nas escolas, no propósito de tornar a disciplina mais dinâmica (CAVALCANTI, 1998).

Di Maio (2004) afirma, embasada em suas experiências nesta área, que o software educacional não é somente um modo sofisticado de ensinar, mas antes de tudo é uma metodologia eficiente que resulta em retorno imediato dentro e fora da sala de aula.

Atualmente, o ensino da Geografia passa em todo o mundo por uma fase de transformação, substituindo ainda que de forma gradual o sistema antigo, puramente de nomenclatura e memorização, por uma compreensão científica e de conjunto da matéria, 
o que contribui para a atuação ativa do aluno e coloca o professor como mediador do processo de ensino-aprendizagem. Compete aos professores que se interessem pela Geografia auxiliar os poderes públicos na difícil tarefa de modernizar seu ensino tomando como ponto de partida a atualização das estratégias metodológicas utilizadas em sala de aula.

Assim, o presente artigo foi resultado da observação da utilização do Google Earth como recurso didático nas aulas de geografia de uma escola de ensino médio, oportunizado pelo Programa Institucional de Bolsa de Iniciação à Docência - PIBID. Através dessa análise, percebeu-se a forma como o Google Earth pode ser utilizado como instrumento de representação espacial e ferramenta para análise espacial por alunos e professores.

A escolha do $1^{\circ}$ ano para o desenvolvimento deste artigo deu-se em função dos componentes curriculares abordados tradicionalmente nesta série, uma vez que seu programa - tanto o que é previsto pelos PCN's, quanto pelos livros didáticos e pelo currículo oficial - abordam questões de cartografia e outras ligadas ao meio ambiente, que nos interessa de forma direta.

Desse modo, este trabalho tem como meta demonstrar a importância do uso do Google Earth como recurso didático aplicado no ensino de Geografia, fomentando uma maior interação do aluno com o seu espaço de vivência e procurando analisar as imagens disponíveis no software como auxilio no ensino de questões socioambientais, em especial das áreas urbanizadas, realizando uma pesquisa de caráter exploratório em uma proposta de atividade escolar para uma turma de ensino médio. Foi possível fazer uma análise e discussão do conteúdo e da metodologia empregada e, portanto, contribuir para o estabelecimento de novas perspectivas no ensino de geografia.

\section{$2 \mathrm{O}$ uso de geotecnologias no ensino de Geografia}

Durante várias décadas vêm se discutindo sobre o ensino de geografia e tais discussões permeiam desde a forma como ela é trabalhada pelos professores, a eficácia de alguns recursos didáticos e práticas metodológicas, até a consolidação de alguns eixos 
temáticos considerados chave como, por exemplo, localização e meios de orientação. No contexto atual, vive-se num mundo em que as novas tecnologias surgem numa intensidade vertiginosa e vão constituindo um novo paradigma de sociedade; os aparatos tecnológicos e outros artefatos com uma infinidade de funções prendem cada vez mais a atenção e o tempo das pessoas. E por que não utilizar essas modificações originadas com a revolução técnico-informacional no ensino de geografia?

Para acompanhar as modificações que vêm ocorrendo no mundo atual com o advento das tecnologias, a escola deve se reorganizar e utilizá-las de forma que possam contribuir de algum modo para o aprendizado dos alunos, fazendo menção ao que diz a Lei de Diretrizes e Bases da Educação Nacional, instituída pela Lei 9.394/96, na qual a compreensão das tecnologias faz parte da formação básica do cidadão e, portanto, do papel da escola e de seus professores.

Tomando esse direcionamento, as geotecnologias são entendidas por Fitz (2008, p. 12) como "[...] as novas tecnologias ligadas às geociências e correlatas, as quais trazem avanços significativos no desenvolvimento de pesquisas, em ações de planejamento, em processos de gestão, manejo e em tantos outros aspectos relacionados à estrutura do espaço geográfico". As geotecnologias contribuem para os estudos do meio geográfico, aperfeiçoando os conhecimentos sobre a relação sociedade/natureza e possibilitam a elaboração de projetos de gestão, planos de ordenamentos e reordenamentos territoriais e outras atividades relacionadas diretamente ao estudo do espaço geográfico. Dessa forma, constituem importantes ferramentas didáticas que possibilitam melhor compreender o espaço, a dinâmica oriunda da relação sociedade-natureza.

Diversas tecnologias de geoprocessamento podem ser utilizadas em sala de aula pelos professores de Geografia em diversos conteúdos, visando um melhor aprendizado do aluno conforme destaca Cavalcanti (2002, p. 39),

[...] a cartografia é um importante conteúdo do ensino por ser uma linguagem peculiar da geografia, por ser uma forma de representar análises e sínteses geográficas, por permitir a leitura de acontecimentos, fatos e fenômenos geográficos pela sua localização e pela explicação dessa localização. Os alunos podem ter a oportunidade de construir seus 
mapas, suas representações de realidades estudadas, aplicando esquemas mentais já adquiridos ou aprendendo elementos da cartografia para representar melhor a realidade. Os alunos precisam ter, também, a oportunidade de ler mapas, de localizar fenômenos, de fazer correlações entre fenômenos. Afirma que o mapa é a imagem mais forte da geografia na escola.

Apoiado nas categorias de análise da ciência Geografia, nos usos e aplicações de softwares livres, a exemplo do Google Earth, pelo qual se obtêm imagens em três dimensões da superfície terrestre, é possível perceber os padrões de ocupação do espaço, fazer estudos de população e de sua distribuição no espaço geográfico, a configuração dos territórios, os elementos do meio físico em sua dinamicidade permanente, enfim, é possível ao professor de Geografia fazer uso de uma ferramenta que possibilite mais aplicabilidade às suas aulas.

\section{Materiais e métodos utilizados}

A presente pesquisa foi desenvolvida com alunos do $1^{\circ}$ ano do ensino médio da Escola Pública Estadual Maria de Lourdes Rêbelo, na cidade de Teresina (PI), assistidos pelo subprojeto de geografia do PIBID, cuja finalidade principal foi a utilização do software Google Earth como recurso didático nas aulas de geografia.

Metodologicamente o presente trabalho foi constituído de três etapas interdependentes: a revisão de literatura sobre a temática das geotecnologias e ensino de geografia e, posteriormente, num segundo momento, foram realizadas as etapas de sala de aula com os alunos e a presença do professor supervisor da área de geografia. Esta etapa compreendeu a aplicação de questionário direto aos alunos com posterior desenvolvimento da aula de exposição. Inicialmente, foram levantadas algumas indagações com os alunos acerca das geotecnologias por meio de um questionário com três perguntas (Você faz uso do Google Earth? Gostaria de utilizar o Google Earth? Utiliza o Google Earth para qual finalidade?). A partir das respostas foi possível traçar um roteiro para execução de um exercício prático com os alunos para avaliar os impactos da 
utilização do software no processo de ensino-aprendizagem nas aulas de geografia, constituindo a terceira fase do desenvolvimento metodológico proposto.

Na segunda etapa do percurso metodológico, procurou-se investigar o contato dos alunos com as geotecnologias por meio dos instrumentos de pesquisa supracitados. No terceiro momento da aula, foi realizada uma atividade/aula prática com a finalidade de interpretar as imagens orbitais e as respectivas ferramentas disponibilizadas pelo aplicativo, priorizando-se questões de cunho ambiental, promovendo no ambiente salaaluno a proposta das geotecnologias como advento no processo da pesquisa e extensão extra-sala de aula e produzindo informações relevantes como extração dos dados espaciais como mapas temáticos regionais, gráficos e tabelas, bem como outros produtos georreferenciados. Foi realizada uma pesquisa de caráter exploratório referente a questões ambientais, em especial das áreas urbanas e/ou com maior intervenção antrópica da cidade de Teresina (PI), sendo possível fazer uma análise e discussão do conteúdo e metodologia empregados durante a aula. Para o desenvolvimento desta última etapa da aula, foi necessária a utilização de celulares do tipo smartphone, ou similares que suportassem o download e utilização do software pelos alunos, conforme a tabela 01.

Tabela 01 - Percurso metodológico

\begin{tabular}{|c|c|}
\hline Etapas metodológicas & Descrição das etapas \\
\hline $\begin{array}{l}\mathbf{1}^{\text {a }} \text { Ação Metodológica } \\
\text { Desenvolvida na Universidade, no âmbito } \\
\text { do planejamento com o grupo de Bolsistas } \\
\text { do PIBID. }\end{array}$ & $\begin{array}{l}\text { Foi executada a revisão de literatura sobre } \\
\text { a temática das geotecnologias e ensino de } \\
\text { geografia, bem como a construção do } \\
\text { roteiro de perguntas do questionário e da } \\
\text { aula. }\end{array}$ \\
\hline $\begin{array}{l}2^{\text {a }} \text { Ação Metodológica } \\
\text { Desenvolvida na Escola Lourdes Rebelo } \\
\text { com alunos. Esta etapa contou com o } \\
\text { auxílio dos bolsistas do PIBID e do } \\
\text { professor titular. }\end{array}$ & $\begin{array}{l}\text { Esta etapa consistiu na investigação do } \\
\text { contato dos alunos com as geotecnologias } \\
\text { por meio dos instrumentos de pesquisa e } \\
\text { foi desenvolvida com base na aplicação } \\
\text { direta de questionários aos alunos. Logo } \\
\text { em seguida, foi realizada a aula expositiva } \\
\text { dialogada. O conteúdo da aula foi } \\
\text { previamente planejado tendo como foco: }\end{array}$ \\
\hline
\end{tabular}




\begin{tabular}{|l|l|}
\hline & $\begin{array}{l}\text { a evolução da cartografia, cartografia } \\
\text { aplicada à geografia, localização com } \\
\text { Google Earth, as geotecnologias e noções } \\
\text { de sensoriamento remoto. }\end{array}$ \\
\hline $3^{\text {a Ação Metodológica }} \begin{array}{l}\text { Foi realizada uma atividade prática com a } \\
\text { Desenvolvida na Escola Lourdes Rebelo } \\
\text { com alunos. Esta etapa contou com o o } \\
\text { auxílio dos bolsistas do PIBID, do do } \\
\text { professor titular e foi desenvolvida na na } \\
\text { própria sala de aula com uso de aparelhos de interpretar as imagens } \\
\text { celulares do tipo Smartphone. }\end{array}$ & $\begin{array}{l}\text { orbitais e as respectivas ferramentas } \\
\text { disponibilizadas pelo aplicativo, } \\
\text { priorizando-se questões de cunho } \\
\text { ambiental. As etapas dessa aula ou } \\
\text { atividade prática consistiram em: } \\
\text { instalação do Aplicativo Google Earth, } \\
\text { manuseio das principais ferramentas, } \\
\text { comparações de imagens em 3D, mapas } \\
\text { digitais, localização, escalas e aplicação } \\
\text { das ferramentas. }\end{array}$ \\
\hline
\end{tabular}

Fonte: Pesquisa direta (2015). Org. Autores

Segundo Carvalho (2012), o uso das imagens de satélite cria a oportunidade para averiguação dos conhecimentos prévios dos alunos, para que os mesmos venham a estabelecer novas relações e tenham mais condições de captar dados e elaborar respostas de uma determinada localidade conhecida ou não de sua rotina habitual. A ideia dessa proposta de ensino foi criar possibilidades de aprendizado da Geografia a partir do eixo de atividades complementares propostas no âmbito do PIBID, através do uso do recurso do Google Earth sobre a orientação do professor, contando com um modelo sugestivo que exemplificará a intenção desse estudo.

\section{Resultados e discussões}

Durante o processo de utilização do Google Earth foi possível promover a capacitação sobre sua utilização, bem como sobre o uso de imagens cotidianas a fim de localizar e (re)conhecer o espaço do qual os estudantes fazem parte.

A possibilidade oferecida pelo Google Earth para realizar estudos comparativos entre diferentes regiões e cidades propicia ao aluno uma riqueza de detalhes que antes, por meio de livros e atlas, seria impossível, tamanha a interatividade. O uso das 
geotecnologias desperta a curiosidade do aluno, mobiliza um conjunto de competências e habilidades, permite ainda a percepção de relações que se materializam no espaço geográfico com maior clareza, o que não é possível nos mapas ou imagens impressas. 0 conhecimento prévio das áreas a serem estudadas em relação às imagens é um grande facilitador e motivador da aprendizagem, tornando a compreensão e construção do conhecimento muito mais rápida e eficaz.

Com a inserção desta ferramenta, pôde ser observada uma maior motivação para o trabalho docente devido ao seu poder de interação de colocar o aluno em uma posição funcional, tornando seus ofícios mais significativos. Permitiu-se a alunos e professora a construção de conceitos, diferentes do que ocorre quando se utilizam as práticas pedagógicas habituais que remetem ao método mnemônico típico do ensino tradicional.

Dentro do primeiro momento após a aplicação do questionário, composto por três perguntas diretas aos 32 (trinta e dois) alunos da $1^{\text {a }}$ série do ensino médio, foi realizada uma aula expositiva dialogada para que os alunos pudessem conhecer um pouco sobre as funcionalidades básicas do aplicativo; o que se constatou foi entusiasmo e envolvimento por parte dos alunos, até então dispersos, uma vez que para muitos aquele era o primeiro contato com o software, ainda que indiretamente.

Através da pesquisa foi possível constatar que $87 \%$ dos alunos não utilizavam o Google Earth, e apenas 13\% utilizavam o aplicativo para alguma finalidade. O que permite evidenciar de forma clara que o software não faz parte do cotidiano de muitos alunos, seja por falta de conhecimento ou de acesso.

O segundo questionamento reportou-se à finalidade do uso feito pelos alunos. Quando questionados, a grande maioria, cerca de 50\%, afirmou que usava para localizar sua cidade, seus bairros e ruas e locais desconhecidos, para onde muitos iriam viajar e queriam conhecer previamente. Outros alunos, cerca de $25 \%$, afirmaram que utilizavam a ferramenta para visualização de mapas e representações cartográficas. E por fim, os que usavam para visualizar imagens de satélite, também exatos $25 \%$ do total.

No terceiro momento, procedeu-se com uma atividade prática do estudo virtual do meio, orientada por um roteiro. Deve-se salientar que sobre a noção de estudo do 
meio, Pontuschka (2007) conceitua essa atividade como uma prática educativa que exercita a construção do conhecimento, para além dos livros didáticos, portanto, é uma metodologia de ensino que busca trabalhar a realidade local dos alunos além dos muros da escola, fazendo com que esses possam despertar para a realização de uma leitura crítica da realidade e para a busca de sua autonomia, pensando dessa forma em ações de intervenção para o exercício de sua cidadania.

O primeiro procedimento foi a instalação do aplicativo, nos aparelhos Smartphones dos alunos, disponibilizado gratuitamente pela empresa Google. (Ver figura 01). Uma vez que a escola dispunha do laboratório, mas os computadores estavam inutilizados, a utilização do aparelho celular se mostrou bastante eficaz no desenvolvimento da atividade. Baseados nos conteúdos até então trabalhados no livro didático, foi feita uma retomada enfatizando os aspectos cartográficos. Devido a essa limitação, os encontros iniciais foram realizados com o uso de um equipamento de projeção de slides, um computador portátil e a rede Wi-fi da escola. Através de conexão com a rede mundial de computadores, foi possível acessar os sites e utilizar os softwares necessários.

Figura 01 - Google Earth para Celulares

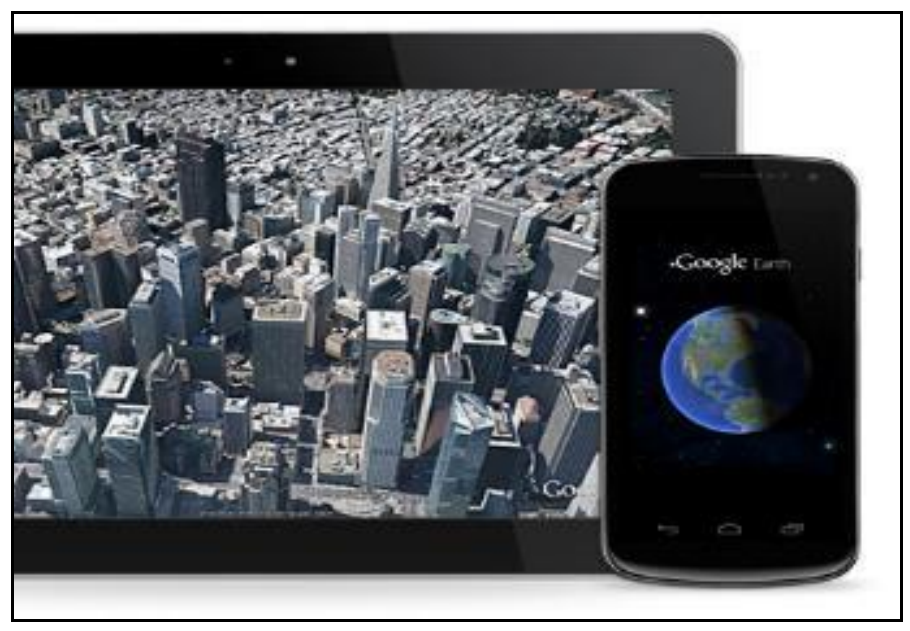

Fonte: GOOLGLE EARTH (2015).

Os principais conteúdos trabalhados com os alunos foram aqueles relacionados à cartografia, sua evolução histórica até os dias atuais, as técnicas de elaboração de mapas 
e obtenção de imagens, escala, localização e paisagens humanizadas que permitiram por parte dos alunos a construção de um embasamento para a aplicação das principais ferramentas do aplicativo disponibilizado em forma de tutorial (Ver tabela 02).

Tabela 02 - Desenvolvimento da atividade prática

\begin{tabular}{|l|ll|}
\hline \multicolumn{3}{|c|}{ Desenvolvimento das aulas } \\
\hline \multirow{2}{*}{ Atividade prática } & $\bullet$ & Instalação do aplicativo Google Earth. \\
& $\bullet$ & Manuseio das principais ferramentas. \\
& $\bullet$ & Comparações de imagens em 3D, mapas digitais. \\
& $\bullet$ & Localização, escalas e aplicação das ferramentas. \\
\hline
\end{tabular}

Fonte: Pesquisa direta (2015). Org. Autores

Destaca-se que as aplicações acima descritas podem ser analisadas nos recortes espaciais local, regional e global. Permitindo, duas abordagens teórico-metodológicas: sintética e analítica. Para Santos (1991), a primeira abordagem caracteriza-se por apresentar o estudo da localidade como ponto de partida, aumentando gradativamente as dimensões espaciais a serem estudadas. Na segunda, o processo é inverso, ou seja, inicia-se com o desconhecido e distante, para depois seguir em direção ao lugar de convivência do educando.

Na barra de menu, podemos encontrar no aplicativo as seguintes opções: Arquivo, Editar, Visualizar, Ferramentas, Adicionar e Ajuda. Utilizando o mouse, é possível aproximar e afastar a imagem do planeta bem como girá-lo em qualquer sentido. Um diferencial significativo existente entre o Google Maps e o Google Earth é a apresentação de imagens tridimensionais. Dessa forma os lugares podem ser vistos de qualquer ângulo. A partir do marcador de localização, por exemplo, é possível estabelecer relações escalares com os alunos, apresentado maior ou menor nível de detalhamento das representações. 
Foi possível executar também a comparação de imagens de satélites dos mesmos espaços em diferentes momentos históricos, por meio da ferramenta e fotos em 3D mostradas na linha do tempo, permitindo a comparação e o levantamento das possíveis causas das alterações verificadas nas paisagens. Com a alternância dos comandos 'satélite' e 'mapa' também é possível transformar o que é uma imagem de satélite em uma representação planisférica com escalas de proporcionalidade, e também a localização exata de qualquer ponto demarcado a partir da rede de coordenadas geográficas que estão estabelecidas sobre o globo.

Esse conceito da localização foi trabalhado a partir da ferramenta do GPS disponibilizada no software, na qual o aluno pode estabelecer a localização de diferentes pontos em qualquer área do planeta e obter a localização precisa a partir da latitude, longitude e também da altitude, possível graças à rede de satélites que orbitam o planeta.

Florenzano (2011), em seu livro Introdução ao Sensoriamento Remoto, apresenta várias contribuições não apenas para o ensino de geografia das imagens de satélite, mas ela reitera a contribuição destas nas diferentes disciplinas. Além de indicar recursos didáticos e cursos disponíveis sobre o assunto, ela sugere um conjunto de atividades para serem aplicadas com os alunos em sala de aula, de modo a permitir que o aluno vivencie conteúdos que até então não se relacionavam com a vida de cada um.

Foram explorados também conteúdos relacionados à parte mais teóricoconceitual do ensino de cartografia: localização, orientação e escala, uma vez que estes conceitos constituem-se como ferramentas fundamentais para interpretação das imagens disponibilizadas pelo aplicativo e que já haviam sido trabalhados em outras oficinas realizadas pelo bolsistas do PIBID de geografia. Inicialmente, os alunos analisaram as imagens disponibilizadas pelo programa e trabalharam com questões de localização, em especial das áreas urbanas. Trabalhou-se em escala local, regional e global. Orientou-se os alunos a identificarem as paisagens com predomínio dos aspectos naturais e aquelas com predomínio dos elementos humanizados, presentes no município de Teresina (PI), e a observar também patrimônios culturais, religiosos e históricos. Os 
estudantes executaram, ainda, "percursos virtuais"” de suas residências até a escola onde estudam; observaram a paisagem de outros ângulos, não somente de forma horizontal, mas também de forma vertical e oblíqua; atentaram para a observação da vegetação, dos rios Parnaíba e Poti que cortam a cidade e identificaram problemas ambientais e a comparação de áreas, o que lhes permitiu fazer algumas constatações.

Enfim, o que constatou-se, em linhas gerais, foi o entusiasmo da maioria da turma, a atenção e interação entre os próprios alunos que puderam verificar a riqueza de informações proporcionadas pelas imagens de satélite e pela utilização de uma ferramenta até então desconhecida da maioria.

\section{Considerações finais}

O Google Earth é, de fato, um aplicativo que possibilitou a visualização geográfica e cartográfica por parte dos alunos e vem se tornando, dessa forma, um eficaz recurso didático para o processo de ensino e aprendizagem da Geografia, pois a visualização/interação de imagens de satélite podem ser constituídas por um conjunto de informações dos limites físicos, políticos, e ambientais através de dados vetoriais, compondo perímetros de malhas urbanas de cidades, pontos e linhas, bem como uso de símbolos cartográficos.

A utilização do Google Earth no ensino de Geografia capacita o aluno na compreensão do espaço geográfico, já que insere aspectos inovadores e motivadores no processo de ensino e aprendizagem. A partir desta ferramenta, o aluno é capaz de extrair dados relevantes do espaço em escala local ou global e construir hipóteses reais com as informações disponíveis em um mapa. A atividade de capacitação sobre a utilização do software Google Earth realizada na escola supracitada, teve grande contribuição não apenas para os alunos, mas também para professores à medida que oportunizou o conhecimento e a interação com novas tecnologias até então desconhecida pela maioria. Concomitantemente o exercício contribui de forma significativa para o fortalecimento

\footnotetext{
${ }^{1}$ No contexto colocado, refere-se ao deslocamento virtual realizado pelos alunos com o marcador de localização disponibilizado no menu de ferramentas do Google Earth.
} 
das ações complementares do subprojeto de geografia do PIBID desenvolvido pelos bolsistas.

A partir das informações e discussões apresentadas, podemos afirmar que diversas atividades podem ser desenvolvidas nas aulas de Geografia com a introdução de recursos não convencionais e novas metodologias. Oportunizou-se uma maior interação com o uso do celular, da internet e das diversas ferramentas de multimídias, diferenciando-se do que normalmente ocorre na utilização de práticas tradicionais recorrentes, o que classifica tal disciplina como "matéria memorativa”. Outra situação constatada foi a falta de conhecimentos relativos às geotecnologias por parte do professor, pois cabe a ele construir sua autonomia frente a qualquer recurso ou técnica de ensino. Também é uma competência a ser buscada no processo de formação continuada de profissionais que desejem estar em sintonia com as mudanças do mundo frente à educação.

Sendo assim, a utilização do software Google Earth para o ensino da geografia, é uma ferramenta complementar, e não deverá ser usada de forma aleatória sem planejamento prévio, sendo necessário serem trabalhados, em sala, pelo professor, os temas e conteúdos a serem abordados, devendo também, definir no início da pesquisa os objetivos que se buscam atingir dentro do processo de ensino, antes, durante e depois do estudo.

\section{Referências}

BRASIL. Ministério da Educação e do Desporto. Secretaria da Educação Fundamental.

Parâmetros Curriculares Nacionais. Brasília: MEC/SEF, 1999.

CARVALHO, Vânia Maria Salomon Guaycuru de. Sensoriamento remoto no ensino básico da geografia: definindo novas estratégias. Rio de Janeiro: Editora APED, 2012.

CAVALCANTI, Lana de Souza. Geografia, escola e construção de conhecimento.

Campinas, SP: Papirus, 1998.192p , Lana de Souza. Geografia e Práticas de Ensino. Goiânia: Alternativa, 2002. 
DI MAIO, Angélica Carvalho. Geotecnologias digitais no ensino médio: avaliação prática de seu potencial. 2004. 188p. Tese (Doutorado em Geografia - Análise da Informação Espacial) - UNESP, Rio Claro. 2004

FITZ, Paulo Roberto. Geoprocessamento sem complicação. São Paulo: Oficina de Textos, 2008.

FLORENZANO, Tereza Galloti. Iniciação em sensoriamento remoto. 3. ed. ampl. e atual. São Paulo: Oficina de textos, 2011.

GOOGLE EARTH PARA CELULARES. Disponível em < https://www.google.com.br/earth/explore/products/mobile.html > Acesso em: 24. Nov. de 2015.

PONTUSCHKA, Níbia Nacib Pontuschka; PAGANELLI, Tomoko lyda; CACETE, Núria Hanglei. Para ensinar e aprender geografia. São Paulo: Cortez, 2007.

SANTOS, Márcia Maria Duarte dos. O uso do mapa no ensino aprendizagem da Geografia. Geografia Rio CLARO, 16, 1991.

Recebido em: 31/07/2016 Aprovado em: 24/10/2017

Universidade do Estado de Santa Catarina - UDESC Centro de Ciências Humanas e da Educação - FAED

Revista PerCursos Volume 18 - Número 38 - Ano 2017 revistapercursos@gmail.com 